\section{REJOINDER TO DEJNOŽKA'S REPLY}

\author{
ArTHUR FaLK \\ Philosophy / Western Michigan University \\ Kalamazoo, MI 49008-5022, USA \\ FALK@WMICH.EDU
}

regret that my review of The Ontology of the Analytic Tradition and Its Origins misleads readers of this Journal about some of its theses. Although I regularly warn my students about mistaking a sufficient condition for a necessary and sufficient condition, my review contains that mistake at least twice. First, according to the book, a philosopher's engaging in paraphrase into a canonical notation is only sufficient for his being an analyst, not both necessary and sufficient, as I implied. More central to my criticism of the book, I also mistook a sufficient condition for being a modified realist as a necessary and sufficient condition. I failed to weight the author's method of uncovering analogies between positions-likenesses, not samenesses between them. If I had weighted the analogizing properly, I would have had to characterize a modified realist as one who either accepts the distinction between distinctions of reason and real distinctions, or accepts something sufficiently like that. This correction does weaken my criticism that the author imposed an alien conceptual framework on the philosophers he analyzed. For the alien conceptual framework was that distinction of distinctions. The philosophers may not have accepted that distinction, but they may have accepted something sufficiently like that to be modified realists. The irony of this is that, alas, I am the one who imposed an alien conceptual framework on the book I reviewed. How my ears do burn.

I also erred in my table of the kinds of analysts by entering the post-1892 Frege in the column reserved for meaning atomists, pending his explicit denial of the atomism. In a recent article which Dejnožka calls to my attention, Dummett affirms Frege's continued allegiance to the context principle,' thereby denying meaning atomism for him. But I would continue faulting Frege after 1892 for no longer stating the asymmetry between sentences and sub-sentential units in the determination of meaning. Contrary to Dejnožka's reading of it, Dummett's article gives me no reason to withdraw that criticism. Dummett says,

It is true that the new formulation [of the context principle in 1893] fails to give a distinguished role to sentences, as the formulation of the Grundlagen had done, and, in consequence, has a greater appearance of circularity. In practice, however, the difference between the old and the new formulations is not significant, since all the primitive functions that Frege has to consider are concepts or relations, so that the "more complex terms" considered are all in fact sentences. (P. I5)

It's not that the distinguished role of sentences in the 1884 version, versus their anonymity among the "more complex terms" in the 1893 version, is not significant, but that it is not significant in practice, since Frege's practice was to give sentences a distinguished role anyway. So I say Frege was at fault in I893 for underdescribing the principle his practice conformed to.

Having admitted much error, I am not in a strong position to insist there remains much that is correct about my criticism of the book. Nevertheless I do think there is. I stand behind my central claim that the book missed the analytic movement's deflation of ontology. My simplistic charge that the book imposed an alien interpretive framework on the movement was my attempt to explain why the book missed the deflation of ontology. Although the explanation fails, the explanandum does not go away. As I read Dejnožka's reply, he thinks he can be on both sides of the fence, finding his analysts did deflate ontology and also that they believed in a modified realist ontology. But the purported evidence for this can be explained in a less paradoxical way by appeal to the distinction Quine made between ontology and ideology, which I mentioned (p. I69). ${ }^{2}$ Quine's realism (and I would argue the later Russell's, too) is a matter of ideological commitment, not ontological commitment: the world instantiates a theory like contemporary science's, with no distinction being made between ontological transforms of the theory. I also mentioned (p. I74 n.26) the recent discovery of the empirical equivalence of theories differing about which items are simple and which compound, a discovery that seems to vindicate the analysts' deflation of ontology and concomitant inflation of ideology. (But I misreported that discovery; the word "soliton" in my review should have been "monopole".)

In my review's last paragraph, I mentioned that identity conditions are themselves structures and so themselves have the identity conditions of structures, which yields another way we can get to the deflation of ontology. In his reply, Dejnožka misreads me as referring not to the conditions themselves, which are structures, but rather to what those conditions are about, 
which are not structures. This is not the only instance where he misreads me: I never said "words [in contrast to sentences] are units in speech acts." In fact I said the opposite (p. I66). So it appears that Dejnožka is quite as capable of misreading as I am. That leaves you, dear reader, with the necessity of not taking either of us as gospel, but of having to sort it all out for yourself. Actually, that's where the fun begins. 